\title{
RAZÃO PRÁTICA, DIREITO E BEM COMUM NA TEORIA DA LEI NATURAL DE JOHN FINNIS
}

\author{
Victor Sales Pinheiro ${ }^{1}$
}

Horácio Lopes Mousinho Neiva ${ }^{2}$

\begin{abstract}
Resumo: Baseado no método hipotético-dedutivo, investiga os conceitos centrais da teoria de justiça de John Finnis, a partir da sua teoria da razão prática substantiva, voltada ao florescimento humano pela realização de bens humanos básicos. O problema de pesquisa é a questão teórica da normatividade da razão prática na vinculação do direito ao bem comum, que exige uma reflexão metodológica sobre a natureza da teoria social.

Para tanto, contextualiza a inserção de Finnis no debate liberal-comunitário, sobretudo pela sua crítica ao conceito restritivo e excludente de razão pública de Rawls. Em seguida, estudam-se os fundamentos metaéticos teleológicos da razão prática. Ademais, verifica-se como o bem comum desponta da ética dos bens humanos básicos e da razoabilidade prática, numa articulação de ética e direito. Depois, articula-se o conceito de bem comum na sua dimensão instrumental e substancial, a fim de sublinhar a relação de liberdade e integração social, pela unidade da razão prática e seu alcance público. Como resultado, ressalta-se o mérito epistêmico dessa teoria, por relacionar a ética dos bens humanos básicos com a autoridade jurídico-político do bem comum. As contribuições desse estudo são a recepção de um autor relevante, o seu aprofundamento conceitual, com o consequente enriquecimento da discussão teórica.
\end{abstract}

Palavras-chave: Razão prática. Bem comum. Direito. John Finnis. Lei Natural.

\section{Introdução: inserção de Finnis no debate das teorias da justiça}

Com a publicação de Uma teoria da justiça, em 1970, John Rawls (2002) renova o debate da teoria política normativa, no âmbito da tradição filosófica analítica. A partir desse grande marco intelectual, uma série de autores responderam às suas poderosas indagações sobre os princípios político-institucionais que estruturam uma sociedade justa.

A discussão que se deu em torno às teses de Rawls ficou conhecido como debate liberalcomunitário, seja pelas respostas que o consideram insuficientemente liberal, como o libertarianismo de Robert Nozick (2011), seja pelas réplicas que apelam para a noção de bem comum e tradição social, como o comunitarismo de Michael Sandel (2005), sem prejuízo de

\footnotetext{
${ }^{1}$ Graduado em Direito pelo CESUPA. Mestre (PUC-RJ) e Doutor (UERJ) em Filosofia. Professor do Programa de Pós-Graduação em Direito (PPGD) da Universidade Federal do Pará (UFPA). Instituição: Universidade Federal do Pará. Brasil. E-mail: vvspinheiro@yahoo.com.br

${ }^{2}$ Graduado em Direito pela Universidade Federal do Piauí (2011), Mestre (2016) e Doutorando em Filosofia e Teoria Geral do Direito pela Faculdade de Direito da Universidade de São Paulo. É professor do Centro Universitário UNINOVAFAPI e da Escola de Direito Aplicado do iCEV - Instituto de Ensino Superior. Instituição: Centro Universitário UNINOVAFAPI.. Brasil. E-mail: horacioneiva@gmail.com
} 
muitos outros autores que, direta ou indiretamente, engajaram-se nele, conforme a reconstituição realizada por Gargarella (2008).

Porém, não se pode negligenciar a importante crítica a Rawls por John Finnis (2011a), que, com a publicação de Lei natural e direitos naturais, em 1980, apresenta uma robusta teoria da justiça de matriz aristotélico-tomista, em franco diálogo com a filosofia política liberal e com a teoria jurídica positivista.

Sua obra cumpre um arco que vai da metaética à ética normativa, do direito à política. Trata-se de uma obra extensa, que demanda uma interpretação sistemática. Ela é marcada pela interlocução com os principais autores de seu tempo, sobretudo John Rawls, na teoria política, e Herbert Hart, Ronald Dworkin e Joseph Raz, na teoria jurídica, sem mencionar a sua profícua interlocução com os filósofos morais modernos como David Hume e Immanuel Kant (FINNIS, 2011b).

Seu mérito principal nos parecer ser o de oxigenar a reflexão contemporânea com a contribuição de autores clássicos como Aristóteles e Tomás de Aquino. No tocante à teoria da justiça, de que se ocupou este Artigo, a renovação do conceito de bem comum, a partir de uma concepção substancial, e não apenas instrumental, de razão prática, é relevante para refletir sobre as dificuldades de fundamentação ética das filosofias políticas que esposam teorias restritivas e deflacionadas do bem, como a de Rawls.

Com efeito, desde a resenha à obra-prima de Rawls, em 1973, Finnis (2011c) sempre teve nele um interlocutor privilegiado, sobretudo por questionar o seu conceito de "razão pública", a partir de sua concepção substancial e cognitivista de razão prática (FINNIS, 2011d). A articulação da razão prática no âmbito público se dá em vistas do bem comum, que legitima a autoridade do Estado pela consecução de direitos humanos, que asseguram os bens humanos básicos do florescimento humano. Na sua obra principal, Lei Natural e direitos naturais, Finnis (2007, p.110) menciona, sem aprofundamento, que a tentativa rawlsiana de estabelecer princípios de justiça imparcial e democrática a partir de uma teoria rasa do bem resulta em arbitrariedade, uma vez que Rawls não justifica, filosoficamente, por que, não se deva atribuir valor intrínseco a formas básicas de bem como a verdade, o jogo ou a amizade, restringindo-se a bens primários como liberdade, oportunidade, riqueza e amor-próprio. Provavelmente, os textos em que Finnis debate mais diretamente com Rawls são 'Limited government' (FINNIS, 2011e), de 1996, e 'Public Reason and moral debate', de 1998 (FINNIS, 2011f). Neste último, Finnis (2011f, p. 259) reconhece o mérito de Rawls de ter introduzido o termo "razão pública" na discussão da teoria política contemporânea, ainda que de modo arbitrário e confuso. 
A hipótese geral da leitura de Finnis é que o princípio de legitimidade, proposto por Rawls em Liberalismo político, de 1993, acaba por excluir certos argumentos da esfera pública, taxando-o de ilegítimos por serem morais, metafísicos ou religiosos, sem verificar sua falsidade ou verdade. Ou seja, o apelo por uma razão pública abrangente e universal, que pudesse ser aceita por todos os cidadãos, resulta na exclusão infundada de várias concepções abrangentes, consideradas a priori como irracionais do ponto de vista político. Por isso, esse princípio não cumpre a equidade e imparcialidade desejadas.

De todo modo, Finnis se apropria, criticamente, do conceito rawlsiano de razão pública, ao considerar que ele expressa quatro características essenciais do pensamento político clássico:

(1) a função do direito é limitado, visando a manutenção da paz e da justiça nas relações interpessoais. Por isso, como se verá adiante, o bem comum é instrumental, uma vez que o direito não almeja tornar as pessoas boas moralmente, mas permitir que elas realizam seus planos individuais de vida, no limite da razão pública. Esta, porém, não se opõe à razão privada, já que as razões para ação são inteligíveis, e, por isso, compartilháveis. Assim, as deliberações da comunidade política delimitam as exigências razoáveis de justiça e de paz, no que Aquino chama de bem público.

(2) Na determinação desse bem público instrumental, o direito aduz razões acessíveis a todas as pessoas, independente de suas convicções religiosas ou práticas culturais. São precisamente esses princípios que a tradição clássica denomina "lei natural", uma vez que baseados na razão prática.

(3) O termo razão pública também expressa o caso central do direito, como coordenação racional de pessoas livres, as quais são tratadas como parceiras, capazes de entender, participar e criticar as diretrizes jurídicas de caráter eminentemente público.

(4) O fundamento último da autoridade jurídica-política do Estado são as razões naturais, universalmente aceitas, do bem comum.

O ideal normativo de Finnis é a razoabilidade prática, pensada como bem humano básico, cuja realização adequada (virtude), é a justiça política, a partir de instituições de direito positivo que assegurem o bem comum, entendido como o horizonte de realização dos planos individuais de vida, isto é, os meios pacíficos de convivência social segura e equilibrada com base em direitos morais (humanos ou naturais-racionais).

Este artigo investiga, portanto, os conceitos centrais da teoria de justiça de John Finnis, bem comum, composto pelas exigências de justiça que são os direitos que promovem e protegem os bens humanos básicos, no contexto da normatividade da razão prática e da metodologia da teoria social reflexiva. 


\section{Razão prática e a metodologia da teoria social reflexiva}

No âmbito da teoria da lei natural de Finnis (2011g, p. 201), o ponto de partida é sempre uma tomada de consciência metodológica do procedimento da razão prática no interior da teoria social (moral, política, jurídica). Por isso, não se compreende a razão prática normativa, nem a autoridade do bem comum que dela deriva, sem relacioná-los aos bens humanos básicos. Eles constituem o bem comum, cujas exigências constituem um requisito da razoabilidade prática. Isto é, ninguém é plenamente razoável, e portanto feliz, se desprezar o bem comum. Aqui, percebe-se uma reciprocidade entre o princípio ético da realização humana e o princípio jurídicopolítico do bem comum a partir do bem humano básico da razoabilidade prática (FINNIS, 2007, p. 127,154$)$.

Como se percebe, o argumento de Finnis é virtuosamente circular para manter a coesão interna de seus pressupostos, que são logicamente costurados. A normatividade da razão prática é essencial para afirmar a autoridade do direito, como atualização da potência da razão prática para coordenar a ação individual e social com vistas ao bem comum, que compreende a realização dos bens humanos básicos. Ao instanciar o bem humano básico da razoabilidade prática (que é como Finnis denomina a virtude aristotélica clássica da prudência), o agente moral atualiza uma inclinação natural de que depende a sua felicidade, contribuindo para a felicidade da comunidade política a que pertence.

De outra parte, para fazê-lo, ele depende do horizonte de liberdade, segurança, direitos e justiça propiciado pelo bem comum. Uma sociedade totalmente desarrazoada, que não respeitasse as exigências mínimas de justiça que são os direitos humanos, impediria a razoabilidade prática individual, na consecução de um plano razoável de vida, isto é, um plano que integre o bem comum na sua ação individual.

Uma postura radicalmente atomista, egoística e antissocial é afastada por Finnis como atentatória à própria razoabilidade do indivíduo, de que depende o seu florescimento. É o próprio bem da razoabilidade que funda a normatividade da autoridade do Estado, como instituição de direito positivo promotora do bem comum.

O erro fundamental de teorias da justiça que, na esteira de Rawls, pressupõem teorias emaciadas, restritivas de bem é cindir a razão prática na sua dimensão privada e pública, como se não fosse o mesmo agente racional a atuar com a finalidade inteligente dos bens básicos na esfera pública (FINNIS, 2011h, p. 95). A consequência disso é uma desintegração da personalidade individual e a neutralização dos argumentos morais substanciais no espaço público, exatamente o local em que se decidem o modo de realização social do bem comum. 
Nesta seção, acompanha-se a própria ordem expositiva de Finnis nas suas duas obras principais, Lei Natural e Direitos Naturais (FINNIS, 2007) e Aquinas (FINNIS, 1998), e na organização de seus Ensaios reunidos (FINNIS, 2011b), que partem da Metodologia à Ética, da Ética ao Direito, do Direito à Política e da Política à Metafísica. Pelos limites desse Artigo, não podemos avançar a esse último e mais denso eixo de sua especulação teórica, que compreende Teologia Natural e Religião, consoante a filosofia de Aristóteles e Aquino.

Composta por dois capítulos, a primeira parte de Lei natural e direitos naturais é dedicada a essa elucidação metodológica preliminar, que apresenta os fundamentos epistemológicos da teorização de Finnis. Se esses pressupostos forem negados, todo o edifício desmorona. Por outro lado, assentadas essas premissas, a arquitetura teórica erigida se apresenta consistente (FINNIS, 1983; FINNIS; BOYLE, GRISEZ, 1987a e 1987b).

Segundo a metodologia adotada por Finnis no primeiro capítulo de Lei Natural e Direitos Naturais, a teoria social (política) descritiva exige a consideração do ponto de vista prático (moral), porque considera as instituições de direito positivo como fatores da normatividade da razão prática, por isso essas instituições são dotadas de autoridade, por promoverem e garantirem os bens humanos básicos e os requisitos de razoabilidade prática.

Como os bens humanos básicos são autoevidentes, e a razoabilidade prática é um bem humano básico, o direito figura como uma instituição positiva da razoabilidade prática em vistas ao requisito do bem comum, com a finalidade de coordenar a ação social a partir dos critérios da justiça, que são os direitos naturais ou humanos. O começo de Lei Natural e Direitos Naturais condensa bem esse argumento:

Existem bens humanos que só podem ser garantidas por meio das instituições do direito humano e requisitos de razoabilidade prática a que apenas essas instituições podem satisfazer. O objetivo deste livro é identificar esses bens, e esses requisitos de razoabilidade prática, para assim mostrar como e sob que condições tais instituições têm cabimento e de que maneiras podem ser (e frequentemente são) deficientes (FINNIS, 2007, p.17).

Nesta passagem, o autor articula [1] a teoria moral dos bens humanos e da razoabilidade prática com [2] a teoria jurídica do direito positivo a partir da [3] metodologia analógica do caso central e periférico. Sem a autoridade, o direito não seria fruto da razão normativa. Sem bem comum, a autoridade do direito seria arbitrária, autoritária. Por isso, a necessidade de entender a metodologia do caso central e da teleologia da ação humana, para se chegar a ética dos bens humanos básicos e da razoabilidade prática, a qual contém o bem comum como um dos seus requisitos. 
O bem comum se realiza pela autoridade do direito, conferindo a este último razoabilidade prática. Isto é, a realização, o acesso e a promoção dos bens humanos básicos, ao configurar o bem comum, legitimam a autoridade do direito. A maior parte das incompreensões acerca da teoria de Finnis descuram essa articulação interna, a virtude circular do argumento que se costura a cada ponto com o anterior e abre o pensamento ao posterior.

Se o desdobramento lógico da questão ética dos bens humanos básicos e da razoabilidade prática surge como necessidade metodológica da teoria normativa da descrição avaliativa, a questão do bem comum e da autoridade derivam diretamente dessa metodologia da razão prática e da ética dos bens humanos.

Essa estrutura argumentativa transparece na sequência de capítulos da obra-prima de Finnis, Lei natural e direitos naturais: a questão dos bens humanos surge da metodologia do ponto de vista prático (do Cap. I, 'Apreciação e descrição do direito', ao III, 'Uma forma básica do bem: conhecimento', e IV, 'Os outros valores básicos'); a razoabilidade prática é um bem humano básico, cujos requisitos são analisados em capítulo próprio (do Cap. IV ao V, 'Os requisitos da razoabilidade prática'); entre os requisitos da razoabilidade prática está o bem comum (do cap. V ao VI, 'Comunidade, comunidades e bem comum'); o bem comum exige a realização da justiça e dos direitos humanos, naturais ou morais (do cap. VI ao VII, 'Justiça', e VIII, 'Direitos'); para realizar o bem comum, o direito goza de autoridade para coordenar a ação social dos cidadãos a ele racionalmente submetidos, por meio de leis que gerem obrigação moral e jurídica, exceto as gravemente injustas por serem contrárias ao bem comum e aos direitos humanos (do cap. VI-VIII ao IX, ‘Autoridade', X, 'Lei', XI, 'Obrigação', e XII, 'Leis injustas'). Nessa articulação da normatividade da razão prática e autoridade do bem comum repousa a teoria da justiça de Finnis.

Não se pode fazer teoria social sem a eleição do caso central que permite a descrição da realidade jurídica. $\mathrm{O}$ caso central depende do significado focal da instituição em análise. $\mathrm{O}$ significado focal, por sua vez, depende da finalidade da prática humana estudada. O direito, para Finnis, tem como finalidade fornecer aos agentes que dele participam uma orientação prática que seja moralmente aceitável (COELHO, 2016). Por isso, o caso central do direito é a ordem jurídica que consegue fornecer uma orientação prática moralmente aceitável. O significado focal é o conjunto de características que permitem às ordens jurídicas mais representativas fornecer uma orientação prática moralmente aceitável. Daí a necessidade de uma teoria moral do florescimento humano, baseada nos bens humanos básicos, na razoabilidade prática, e no bem comum.

Como se vê adiante, no próximo tópico, o bem comum é o conjunto de condições necessárias para a realização dos bens humanos básicos, que constituem o florescimento humano. 
O direito tem autoridade legítima quando serve ao bem comum, promovendo a justiça dos direitos naturais ou humanos. O direito precisa da autoridade para coordenar a ação de modo razoável, permitindo aos seus destinatários assimilar as razões jurídicas como razões para ação com a finalidade do bem comum, que sempre os beneficia, como agentes racionais. Isso porque o bem comum é um requisito da razoabilidade prática. Desconsiderá-lo é desarrazoado e nos priva de parcela da nossa racionalidade comum e pública.

Segundo Finnis, é a ausência de um conceito substancial de bem comum que fragiliza o conceito de razão pública em teorias da justiça de inspiração rawlsiana, uma vez que o caso central do direito é o direito positivo, cuja autoridade política gera obrigação moral por apresentar aos cidadãos formas de cooperação que sejam moralmente aceitáveis, consoante a teoria moral do florescimento humano (FINNIS, 2011i).

Essa é a concepção se subtrai ao relativismo metodológico segundo o qual qualquer teoria descritiva encontraria o mesmo resultado na realidade. Ao contrário, o compromisso do teórico é com a razoabilidade prática das instituições humanas que coordenam a ação dos indivíduos com vistas a fins:

As diferenças de descrição são derivadas das diferenças de opinião, entre os teóricos descritivos, a respeito do que é importante e significativo no campo dos dados e da experiência com a qual eles todos estão igual e completamente familiarizados. (COELHO, 2016)

Não há descrição sem seleção, e essa seleção deve ser racionalmente fundada, porque a ação humana é teleológica, isto é, volta-se a um fim racional, um bem, que, em última instância, instancia um bem humano básico. É necessário, portanto, discernir o caso central dos periféricos e essa metodologia permite distinguir instituições humanas maduras das subdesenvolvidas, os sistemas sofisticados dos primitivos, as instituições prósperas das corruptas.

No cap. II.7 de Aquinas, Finnis (1998, p. 42-47) explica esse método analógico das semelhanças e diferenças, correspondências e assimetrias do caso central como sendo aquele exemplar "sem restrições" ou "simplesmente" (simpliciter), que explicita o significado focal. Dele, divisam-se os casos periféricos, com seus significados secundários, imperfeitos. Os exemplares periféricos de uma prática só podem receber a denominação do caso central (o direito, por exemplo) "em certo sentido", "por assim dizer", "de certo modo" (secundum quid).

E qual é o critério para discernir o significado focal do secundário, o caso central do fronteiriço? Baseando-se na teleologia de Aristóteles e Aquino, a resposta de Finnis é: o ponto de vista prático particular, a perspectiva da ação das pessoas envolvidas na prática do direito. 
Sem a compreensão da finalidade da prática, o bem da ação, não conseguimos descrever corretamente a instituição enfocada.

Na elucidação da sua metodologia, Finnis (2007, p. 29) segue o dispositivo dos tipos ideais de Weber, para quem "as avaliações dos próprios teóricos são um componente indispensável na seleção de quaisquer conceitos a serem usados na descrição de aspectos humanos, tais como o direito ou a ordem jurídica".

Mas Finnis vai além disso, porque procede com uma dialética da descrição social e da avaliação da razoabilidade prática das instituições que descreve, a fim de aquilatar a medida da sua razoabilidade. Nesse ponto, o teórico social alia-se ao filósofo prático, num movimento dialético de "descrições explanatórias do contexto humano no qual o bem-estar humano é realizado e arruinado de inúmeras maneiras" e "avaliação do bem humano e seus requisitos práticos" (FINNIS, 2007, p. 29).

Nesse equilíbrio reflexivo entre ciência social descritiva e filosofia prática, a teoria do direito natural não perde a sua isenção, mas continua "neutra de valores": ela não extrai juízos morais de fatos sociais, nem se reduz a uma apologia de juízos morais e políticos. Ao contrário, por reconhecer a inevitável influência do teórico na seleção do caso central que lhe permite descrever determinada prática, a teoria do direito natural exige que o teórico se torne "cada vez mais reflexivo e crítico, convertendo os seus próprios preconceitos práticos (e os da sua cultura) em juízos altamente razoáveis a respeito do que é bom e razoável na prática” (FINNIS, 2007, p. 29).

Com consciência metodológica do caso central e ponto de vista prático, a teoria do direito natural pretende criticar o ponto de vista prático da instituição do direito a partir da razoabilidade prática, identificando "as condições e os princípios de discernimento prático, da boa e apropriada ordem entre os homens e na conduta individual", numa contribuição "às reflexões práticas daqueles que se preocupam em agir, como juízes, políticos ou cidadãos" (FINNIS, 2007, p. 2930).

É assim que a teoria de Finnis supera a abstração de teorias normativas de pretensão universal. Pelo método analógico, é necessário partir da descrição científica (sociológica, por exemplo), das instituições políticas existentes, a fim de extrair delas, a finalidade racional-moral que buscam realizar.

Ao refletir sobre os princípios de justiça ínsitos a essas instituições positivas, o teórico descritivo alcança o filósofo prático que avalia a razoabilidade desses propósitos práticos. Ele não se descola do seu próprio horizonte de razoabilidade prática; ao contrário, participa ativamente da razão pública, que argumenta sobre o bem comum. O filósofo prático reflexivo 
exerce uma função social importante de elucidação e crítica do bem comum em jogo numa sociedade histórica determinada, pela mobilização de princípios morais (os bens humanos básicos) que compõem, em graus de realização variáveis, a razão pública (FINNIS, 2011j).

\section{Fundamento da razão prática}

Na obra Fundamentos de Ética (1983), Finnis traça as linhas fundamentais de sua metaética, distinguindo a razão prática da teórica, tanto pelo seu escopo quanto pelo seu método.

A razão prática visa a conhecer a ação humana, a partir dos seus fins (bens), consoante a racionalidade humana. Num nível epistemológico, a ação precede o ser, por isso não se deve partir do conhecimento ontológico da natureza humana em abstrato, fornecido pela razão teórica, para, em seguida, derivar dessa natureza o comportamento ético adequado. Ao contrário, conhece-se a natureza moral humana a partir dos fins racionais, que revelam inclinações, que se baseiam na natureza.

$\mathrm{Na}$ esteira de Aristóteles e Aquino, essa questão é crucial para a compreensão da falácia naturalista em que muitos autores modernos incorreram, ao fazerem derivar do conhecimento teórico da natureza humana (ser) os preceitos morais que a realizam (dever ser). Finnis (2012, p. 21) sintetiza seu ponto na seguinte passagem:

O estudo sobre a natureza de um ser, para Aristóteles, é um estudo sobre as potencialidades e as capacidades daquele ser. (...) potencialidades ou capacidades são compreendidas quando se compreendem seus atos (atualizações) correspondentes; e atos ou atualizações devem ser, por sua vez, compreendidos por meio do entendimento dos seus objetos. (...) A Ética não é deduzida ou inferida da metafísica nem da antropologia.

Nesse excerto, vê-se que a metodologia da razão prática afirma a precedência da Ética em relação à Epistemologia, já que o conhecimento da natureza humana não é a base da Ética, no sentido em que certa tradição escolástica passou a pensar. Mas Finnis não quer com isso dizer que a metafísica seja dispensável no estudo da Ética. Ao contrário, um dos méritos da obra de Finnis (2012, p. 21-22) é demonstrar a importância das Filosofias subjacente às teorias sociais normativas:

No entanto, uma metafísica ou uma antropologia equivocada irá bloquear o entendimento reflexivo sobre o modo pelo qual alguém participa dos bens humanos (especialmente o próprio bem da razoabilidade prática). Se, por exemplo, alguém presume que a razão é escrava das paixões, um mero instrumento para organizar e atingir com eficiência desejos que são apenas 
dados antes de todo tipo de entendimento, esse alguém não encontrará qualquer motivo para atribuir às exigências da razoabilidade prática a sua força arquitetônica e conclusiva.

A oposição que se evidencia nesse trecho é a de Hume e o emotivismo moderno, segundo o qual os desejos não são racionais e a razão apenas os justifica. A razão não governa a vontade com vistas a um bem entendido como tal, mas racionaliza expressões dos desejos (FERREIRA NETO, 2015).

O emotivismo moderno, tal como descrito por MacIntyre (2001), é fruto dessa redução da razão prática, da negação da possibilidade de conhecer o que é bom e mal, a partir de critérios de razoabilidade prática que sejam identificáveis por todos e cuja força resida exclusivamente na razão. Segundo essa concepção, apenas o juízo objetivo dos fatos é cientificamente verificável como verdadeiro ou falso. Já o juízo moral valorativo é subjetivo, logo inverificável, insuscetível de qualquer verificação pois fruto de mera preferência pessoal. Os juízos morais apenas expressam e produzem sentimentos. Quando se diz "isto é bom", quer-se significar "eu aprovo isto; aprove você também”.

Finnis demonstra não só que Aristóteles esclareceu a contento a diferença entre razão teórica e prática, mas que Tomás de Aquino também tinha plena consciência disso. No capítulo dedicado à Metodologia da teoria social de Aquinas, Finnis (1998, p. 21) apresenta as quatro ordens da realidade, articuladas às ciências correspondentes, que são irredutíveis entre si: (1) a ordem natural das ciências que não são afetadas pelo nosso pensamento (como a matemática, a metafísica e as ciências naturais da química e da biologia); (2) a ordem lógica das ciências que trazem ordem ao nosso próprio pensamento (como a ciência da lógica em sentido amplo); (3) A ordem ética das ciências relativas à deliberação, escolha e ação voluntária (como a philosophia moralis, que abrange a moral, a economia e a ciência política); (4) a ordem técnica das ciências de uma diversidade de artes práticas, tecnologias e técnicas que trazendo ordem para qualquer tipo de objeto externo ao nosso pensamento e a nossa vontade, produz coisas constituídas pela razão humana (como a arquitetura, a marcenaria e a culinária).

Essas ordens são ontologicamente irredutíveis entre si e não podem ser confundidas no plano epistemológico. O estudo da instituição social jurídico-política do Estado, por exemplo, pertence à terceira ordem, a ética, o estudo das ações humanas voluntárias e autodirigidas pela razão. Nenhum objeto da ordem ética pode ser entendido pelas ordens natural, lógica ou técnica.

Segundo Finnis, na modernidade, os teóricos recaem em metodologias reducionistas ou desviantes, obliterando a compreensão da realidade social e jurídica, por subestimar a capacidade moral da razão, tanto de dirigir o homem quanto de conhecer as suas ações finalísticas. Assim, 
por exemplo, referindo-se especificamente às teorias modernas do direito, Finnis (2011j, p. 111) alega que o realismo jurídico o reduz à ciência natural; o kantismo jurídico, à lógica; e o positivismo jurídico, à técnica. A Ética é uma filosofia da conduta humana autodeterminada, com o direcionamento da vontade pela razão. E a razão se volta a fins inteligíveis, que são os bens que apetecem à razão, conforme o primeiro princípio da razão prática ("fazendo e perseguindo o bem e evitando o mal").

Segundo a interpretação de Grisez (1965), seguida por Finnis, nesse primeiro princípio da razão prática, os termos "bem" e "mal”, não são substanciais, mas princípios pré-morais. Eles apenas condicionam o pensamento prático e a ação humana a agir com vistas a um fim (que seria o bem naquele contexto). Mesmo a ação imoral se dirige a algo que apreende como um bem (SCANDROGLIO, 2012, p. 99-121).

O primeiro princípio é a condição da ação racional humana, afirmando que toda ação moral é autodirigida pela razão com vistas a um fim. Se não houver um bem visado pelo agente, a ação não seria racional, do ponto de vista moral, nem inteligível, do ponto de vista ético. Se, na razão teórica, a verdade alcançada pela inteligência já está realizada no objeto de pensamento, a razão prática alcança a inteligibilidade do fim moral racionalmente visado pelo agente, não a compreensão teórica da verdade do ser.

\section{Bem comum e direito no âmbito da razão prática}

No seu tratado de filosofia jurídica analítica contemporânea, Postema (2011, p. 551-562) divide a teoria da lei natural de Finnis em duas partes: a teoria da razoabilidade prática e a teoria jurídica do direito, da autoridade e do bem comum. Como já explicado anteriormente, esta divisão básica é reconhecida pelo próprio Finnis, pois, numa teoria da justiça pautada na normatividade da razão prática, não se pode fragmentar o argumento ético do argumento jurídico-político como se fossem dois tópicos independentes, contingentemente associados.

Ao contrário, o argumento é ético e jurídico-político do começo ao fim, consoante a metodologia adotada desde o princípio. E isso explica a imprescindibilidade da noção de bem comum para fundamentar a autoridade. Portanto, a divisão entre ética da razoabilidade prática e direito autoritativo do bem comum é lógica e didática, não ontológica.

Não fosse essa unidade entre ética e direito, Finnis seria um dualista: Por um lado, ele seria um jusnaturalista que acredita que a razão prática discerne bem humanos básicos, mas que não é normativa, isto é, não fornece razões normativas para a ação, capaz de efetivamente guiar a conduta dos agentes racionais. Por outro lado, ele seria um juspositivista que acredita que o 
direito reivindica autoridade por emanar de uma instituição capaz de impor diretivas aos cidadãos pelo poder sancionatório de suas ordens.

Desse esquema dualista, ele sempre se furtou, denunciando-o como sendo uma distorção tanto das pretensões jusnaturalistas genuínas, que não são incompatíveis com a lógica do direito positivo, quanto das pretensões juspositivistas, que não exclui conceitualmente a necessidade de fundamentação da autoridade do direito, ainda que a distinga da tarefa epistêmica de descrevêlo.

Como argumentado acima, a teoria do direito de Finnis é situada numa teoria compreensiva da razão prática, fundada no primeiro princípio da razão prática que orienta as ações humanas autodirigidas a bens básicos, que estruturam cada ato para um fim específico. Daí a necessidade de estabelecer quais são esses bens humanos, que consubstanciam os direitos humanos, como exigências da justiça, na esfera jurídica do bem comum. Razões fundacionais da ação, os bens humanos são aspectos essenciais do autêntico florescimento humano.

Depois da listagem inicial de sete bens básicos em Lei natural e direitos naturais (FINNIS, 2007, p. 91-95) - 1. vida; 2. Conhecimento; 3. Jogo; 4. experiência estética; 5. Sociabilidade; 6. razoabilidade prática; e 7. religião -, Finnis reformula essa lista da seguinte maneira: 1. conhecimento da realidade (incluindo a experiência estética de apreciação desta realidade); 2. excelência no trabalho e no jogo (com a qual se transforma as realidades naturais para expressar significados e servir a propósitos); 3. harmonia entre indivíduos e grupos (paz, boa-vizinhança e amizade); 4. harmonia entre os sentimentos e os julgamentos e escolhas (paz interior); 5. harmonia entre as escolhas e julgamentos e a conduta (paz de consciência e autenticidade); 6. harmonia com uma dimensão mais ampla da realidade (incluindo a realidade constituída pela dependência do mundo numa fonte mais-do-que-humana de sentido e valor (FINNIS, 20111. p. 213).

Esse texto de 1992, publicado na importante coletânea Natural Law Theory (GEORGE, 1992), revela a influência da categorização proposta em 1987, no texto "Practical principles, moral truth and ultimate ends" (FINNIS; BOYLE; GRISEZ, 1987a), referido acima, que reformula a lista de bens humanos básicos e os classifica segundo o critério de substância e reflexividade. A categoria da reflexividade é decisiva para a compreensão do bem comum, que pode ser considerado o mais reflexivo dos requisitos da razoabilidade prática, porque pressupõe não apenas a deliberação e escolha do agente moral individual, mas também a cooperação com os demais agentes para evitar as várias formas de conflito interpessoal. O bem comum é a forma superior de harmonia da comunidade política completa. Ele permite a compatibilização 
harmônica dos planos de vida de indivíduos racionais, que assimilam a racionalidade dos demais agentes num plano de igualdade e liberdade.

$\mathrm{Na}$ realização dos bens humanos básicos, cada agente moral se vale do bem da razoabilidade para constituir um plano individual de vida, que é a moralidade da eleição de objetivos de vida e hierarquias de bens. Pré-morais, os bens são incomensuráveis entre si. Cabe a cada um estabelecer as suas prioridades existenciais, conforme seu plano de vida. A moralidade é o resultado da atuação da razoabilidade prática, em atenção aos seus requisitos fundamentais, que estruturam a conduta autodirigida do agente (FINNIS, 2007, p. 128).

O bem humano básico da razoabilidade prática, que a tradição clássica denomina virtude da prudência, estrutura a nossa busca dos bens a partir dos seguintes requisitos: 1. plano coerente de vida; 2. sem preferências arbitrárias por valores; 3 . sem preferências arbitrárias por pessoas; 4. desprendimento e compromisso; 5. relevância limitada das consequências; 6. respeito por cada valor básico em cada ato; 7. as demandas do bem comum; 8. seguir os ditames da própria consciência (FINNIS, 2007, p. 105-127).

Os bens humanos são categoriais, isto é, servem de categorias abrangentes nas quais se enfeixam todas as ações humanas. Todos os bens e valores que motivam as ações humanas são instanciações, participações ou especificações dos bens humanos básicos. Os bens humanos básicos são (SCANDROGLIO, 2012, p.66-81): finais (porque são os fins das nossas ações), normativos (porque estabelecem razões conclusivas para nossa ação), objetivos (porque sua existência não é criação subjetiva ou social), abstratos (precisam ser instanciados e concretizados na experiência moral de cada agente racional), pré-morais (não indicam nenhuma forma moral específica de vida ou modo de atualização), plurais (suas formas de concreção são incontáveis e abertas à diversificação ilimitada), autoevidentes (não são conhecidos pela razão teórica, numa investigação científica metódica, mas pela razão prática, num ato perceptivo de insight no âmbito da experiência concreta; MIRANDA, 2015) e universais (encontram-se em todas as experiências humanas, ainda que em graus diferentes).

De todas as características dos bens humanos básicos, a mais importante para a afirmar a necessidade da autoridade do direito é que eles são incomensuráveis entre si. Por isso, há incontáveis planos de vida, muitos deles incompatíveis entre si. Isso significa que há problemas de coordenação entre agentes racionais. Nem sempre se chega à harmonia apenas pela razão prática dos agentes, por mais que eles estejam dispostos a colaborar e não estejam obliterando a atuação da razão prática por desejos arbitrários e egoístas. O egoísta, que exclui o bem comum de sua reflexão prudencial, priva-se da razoabilidade prática e certamente ameaça a harmonia 
social, desconsiderando o acesso dos outros aos bens humanos, que, em linguagem jurídicopolítica, significa a vedação a direitos humanos dos outros.

Mas é importante frisar que não é só da ausência de colaboração do egoísta que derivam problemas de coordenação. Pela incomensurabilidade dos bens humanos, sobretudo numa sociedade complexa e plural, surgem problemas de coordenação, os quais se resolvem ou por unanimidade ou por autoridade. A autoridade é o recurso da razão prática normativa para solucionar esses problemas a partir das exigências da justiça, dos direitos humanos, que constituem o bem comum (DUKE, 2013).

Para Finnis, o caso central da autoridade do direito é considerar a obrigação legal como obrigação moral, uma exigência premente da justiça e do bem comum. Moral aqui significa razoável do ponto de vista prático (CORREAS, 2006). A expressão razoabilidade prática indica, portanto, razoabilidade moral. A moralidade é o resultado do equacionamento dos bens humanos básicos na constituição de um plano de vida individual. Esse plano de vida é arquitetado a partir dos requisitos da razoabilidade prática, que são o modo como os homens dotados de razoabilidade prática ordenam a sua ação consoante os fins que priorizam na sua vida.

Por causa do bem comum, a razoabilidade prática individual é intrinsecamente pública. Naturalmente, isso não quer dizer que não haja âmbitos irredutivelmente individuais e privados da ação humana, mas, mesmo eles, dependem do bem comum para sua realização, na forma de direitos individuais que constituem as exigências de justiça. Aqui se percebe a dimensão comunitária e política da antropologia filosófica subjacente a essa teoria clássica, de matriz aristotélico-tomista.

Como nota Barzotto (2010), trata-se da antropologia da pessoa humana cuja natureza é política e racional. O que nos vincula em sociedade é a razão pública, a nossa capacidade não só de calcular interesses individuais, como na conceito utilitarista de bem comum agregativo, mas de discernir as exigências fundamentais de justiça inscritas na nossa razoabilidade prática compartilhada, que depende, para tanto, de instituições política de direito positiva para se realizar (MURPHY, 2005).

A razoabilidade prática tem uma dimensão pública e social, que é medida pela existência da autoridade do direito, que assegura o bem comum. Ora, não é arrazoado, nem do ponto de vista moral, nem jurídico, deixar-se vencer por paixões egoístas e impedir o florescimento humano das outras pessoas, igualmente dotadas de razoabilidade prática para estabelecerem suas prioridades morais num plano de vida.

O caso central do direito, portanto, é coordenação racional e a compatibilização, tanto mais quanto possível, da liberdade racional e da autonomia moral das pessoas (FINNIS, 2011m). 
Fornecendo meios de realização do florescimento humano, isto é, apresentando uma orientação prática moralmente aceitável, a razão jurídica torna-se normativa e o direito reveste-se de autoridade. A seguinte passagem de Finnis (2007, p. 27-28) ressalta esse ponto:

Se existe um ponto de vista sob o qual a obrigação legal é tratada como, pelo menos presumivelmente, uma obrigação moral (e, assim, como de 'grande importância', a ser mantida 'em oposição ao impulso das fortes paixões' e 'ao custo de sacrificar considerável interesse pessoal', um ponto de vista segundo o qual a manutenção da ordem jurídica em distinção a uma ordem discricionária ou estaticamente consuetudinária são encarados como um ideal moral, quando não uma exigência premente de justiça, então tal ponto de vista irá constituir o caso central do ponto de vista legal.

A noção racional de bem comum exige que os bens humanos sejam respeitados e promovidos pelo simples fato de que são bens comuns a todos os homens, aspectos do florescimento humano de pessoas individuais. Como ressalta Postema (2011, p. 551-552), "eles [os bens humanos básicos] não têm nenhuma significância normativa abstraída da sua instanciação nas vidas e na personalidade de seres humanos individuais".

Considerando a sua pluralidade e incomensurabilidade, os bens humanos básicos apontam para um ideal abrangente de realização humana integral: a realização de cada ser humano, e suas comunidades, em todos os bens humanos básicos. A partir dessa noção, Finnis formula o princípio moral mais básico: escolha apenas aquelas possibilidades cuja vontade é compatível com a vontade para a realização de todas as pessoas em todos os bens humanos básicos, isto é, para o ideal da realização humana integral, e universal (FINNIS; BOYLE; GRISEZ, 1987, p. 132).

Ser moralmente bom é ser plenamente razoável nas suas deliberações prudenciais. Como os bens humanos básicos são abstratos, a realização de cada um deles e a articulação entre eles, na vida de cada pessoa, é irredutivelmente diversificada (DUKE, 2013). Na tomada de decisões concretas para realizá-los, surgem problemas de compatibilização com bens alheios, o que exige da razão prática a coordenação e conformação das ações individuais num plano de vida coerente. A coerência aqui não significa apenas autenticidade e coesão com a própria, na constituição de uma personalidade duradoura e estável, mas compatível com os planos de vida dos outros agentes racionais.

Isso precisamente constitui a moralidade individual, como expressão da razoabilidade prática. Alguém não pode se dedicar à pesquisa acadêmica, com dedicação integral à vida 
universitária, sem renunciar à possibilidade de ser um atleta profissional, que treina oito horas por dia o seu esporte. A pessoa não poderia escolher essas duas opções existenciais, que instanciam bens humanos básicos diferentes e igualmente valiosos, o do conhecimento e o do jogo, sem violar o bem da razoabilidade prática, que exige um plano coerente de vida. A pessoa pode ser um acadêmico profissional e um atleta amador, ou um atleta profissional e um intelectual amador. As duas atividades exigem uma dedicação abrangente e a excelência em ambas é, normalmente, incompatível.

Analogicamente, tanto quanto a razoabilidade prática normativa atua na determinação e coordenação da ação individual para consecução de um plano de vida coerente, o direito, isto é, o ordenamento jurídico-político do Estado atua, com autoridade, para solucionar problemas de cooperação entre os planos individuais de vida, não raro conflitantes entre si. Mas o cidadão que se vê obrigado pelo direito autoritativo - isto é, o direito cuja autoridade é legítima por servir ao bem comum -, não o obedece por medo de sanção, ou por mero hábito social, mas o obedece porque identifica nele expressão da sua própria razoabilidade prática normativa (OLIVEIRA, 2002).

Ora, um indivíduo não está em condições para coordenar a sua ação com os demais, a menos que tenha autoridade sobre eles. É o direito é a instituição social pautada na razoabilidade prática do bem comum, que procede com esta coordenação, a fim de harmonizar a vida social, garantindo o acesso aos bens humanos básicos por meio dos direitos humanos (AYAR, 2000). Ou seja, a autoridade do direito comensura, em concreto, o que antes era incomensurável, em abstrato, da mesma forma que o agente, ao agir prudencialmente, determina concretamente a sua moralidade a partir das opções que sua razão prática lhe apresenta como boas, os bens humanos básicos.

A teoria jurídico-política de Finis visa a explicar a autoridade do direito positivo, a partir da normatividade da razão prática, que reconhece o bem comum em consonância com o princípio moral mais básico, o da realização humana integral e universal, isto é, a acessibilidade de todos os bens humanos básicos a todas as pessoas.

O direito positivo, portanto, é uma instituição humana convencional e relativa, mas que traz em seu conceito o imperativo racional do bem comum. Pode-se dizer, então, que o direito é a razão prática em comunidade, fornecendo razões para ação para que uma coletividade de indivíduos possa realizar os seus bens de modo harmônico e compatível.

A razão prática não é só individual, arquitetando um plano de vida individual, mas também é pública, estruturando um plano de vida social. Mas isso não implica nenhum tipo de coletivismo ou organicismo que traga os indivíduos numa coletividade abstrata como o partido, 
o estado ou a nação. Ao contrário, a razão pública é um elemento da razão prática individual que age em articulação com outros agentes racionais (CORREAS, 2015).

O direito é um intermediário da cooperação social dos cidadãos que reconhecem a sua interdependência e a necessidade da colaboração para o bem comum. Participar de comunidades já é a realização de um bem humano básico (a sociabilidade), o entanto a participação na comunidade completa do Estado de Direito está plenamente justificada para atender ao princípio da realização humana integral.

A autoridade do direito atua como efetivação prática e equacionamento racional do bem comum, a partir de diretivas de justiça que considerem os direitos humanos, que tutelam os bens humanos básicos. Ou seja, a autoridade do direito determina o modo de realização do conteúdo do bem comum, que são os bens básicos. Sem as medidas concretas do direito - como leis, políticas públicas e decisões judiciais -, o bem comum seria uma abstração.

\section{Bem comum instrumental e substancial}

Para a compreensão do conceito de bem comum, em Finnis, deve-se estabelecer uma interpretação conjunta de suas duas principais obras, Lei natural e direitos naturais (FINNIS, 2007) e Aquinas (FINNIS, 1998). Na primeira, a ênfase é no aspecto instrumental do bem comum, ao passo que, na segunda, Finnis o considera também no seu aspecto substancial. Em ambas, porém, o conceito de bem comum fundamenta a autoridade moral e jurídica do direito.

Para explicitar o conceito finnisiano de bem comum, tomemos um exemplo corrente na vida universitária: uma palestra acadêmica. Ora, essa atividade se caracteriza pela busca de determinados bens comuns, que são as finalidades pelas quais professores e estudantes se reúnem, fins como o conhecimento, a profissão e a sociabilidade. Essa comunidade universitária é uma instituição baseada em determinadas regras.

De alguma forma, o bem do conhecimento pertence, primariamente, ao palestrante, mas não tem origem e nem se limita a ele, pois também pertence aos demais ouvintes. O bem comum é individual sem deixar de ser comum, pois ele não se exaure nos particulares ou em determinada coletividade. O bem comum e o bem individual não se opõem, como receia o pensamento liberal que teme a ideia de bem comum como sendo potencialmente autoritária e inimiga da liberdade e do pluralismo (VALLEJO, 2013). No âmbito do bem comum, a busca compartilhada de bens individuais se dá de forma harmônica, e não antagonista, quando intermedida por instituições políticas de justiça. São essas instituições que preveem as regras justas de cooperação social, a partir dos direitos que asseguram o bem comum. 
Se os direitos individuais se opusessem ao bem da comunidade o direito seria desarrazoado e institucionalizaria um conflito moral insolúvel. Tal direito geraria uma sociedade caótica e essencialmente litigiosa. Todavia, segundo a metodologia analógica adotada por Finnis, o direito que racionaliza o conflito é um caso desviante de direito, porque demite a função jurídica da razão prática de coordenar a ação social para o bem comum (CHALMETA, 2002).

A definição clássica de lei, proposta por Tomás de Aquino (2016, p. 527-528), é: “ordem ou prescrição da razão para o bem comum, promulgada por quem tem o cuidado da comunidade". Essa definição articula a lei à ordem racional e ao bem comum, pois o bem comum é o fundamento racional e moral da autoridade política. Essa relação entre bem comum e o fundamento da lei deve ser entendido no quadro teórico mais amplo definido por Finnis, como se tem enfatizado ao longo deste Artigo (CROWE, 2016).

Toda vida humana, em algum nível, sempre está exercitando e atualizando algum bem humano básico, e não é possível que não esteja. Esses bens humanos são orientados pelos requisitos da razoabilidade prática, já que frui-los é bom e é racional. É a racionalidade desses bens que justificam a existência das instituições, as quais servem para promovê-los e protegêlos, como no caso da instituição universitária que visa ao bem comum do conhecimento e da sociabilidade, no exemplo apenas citado.

A autoridade do direito é racional, porque a consecução dos bens humanos básicos exige o bem comum como requisito. Em Lei Natural e Direitos Naturais, o bem comum é instrumental, baseado na ideia de autoridade a serviço do bem comum, de modo que tais bens serão realizados na vida individual e a liberdade de escolha será importante, mas ela não se estende a uma liberdade tal que implique em irracionalidade de desconsiderar os bens humanos básicos.

Finnis concorda com Raz que a autoridade como fato social reivindica uma autoridade legítima e se baseia em comandos por meio de razões excludentes de segunda ordem, isto é, suspendem o balanço de razões de primeira ordem (FINNIS, 2007, p. 256). Contudo, a pergunta de um teórico da lei natural seria: "por que essa autoridade não seria tão somente formal e autoritária?”. Assim, a teoria da lei natural está preocupada não só com a forma racional da autoridade, mas com o seu conteúdo racional-moral.

Em Lei Natural e Direitos Naturais, há três níveis explicativos para chegar ao bem comum instrumental: (1) os bens humanos básicos são bons para todos aqueles que deles compartilham; (2) os bens humanos básicos são bens básicos que podem ser objeto de participação inexaurível; e (3) o bem comum é constituído das condições que permitem os membros da comunidade atingirem por si mesmos objetivos razoáveis (FINNIS, 2007, p. 155). 
É esta última conceituação é a do bem comum instrumental o que permite que as pessoas atinjam, por si mesmas, os objetivos razoáveis que tiverem estabelecido pela sua razoabilidade prática individual, na arquitetura de seu plano de vida (GREEN, 2013). Mas os objetivos serão desarrazoados se interferirem no plano de vida dos outros, atentando contra os requisitos da razoabilidade prática descritos acima, contra o bem comum, contra certos bens, contra certas pessoas e assim por diante.

Ninguém pode ser obrigado a gozar dos bens humanos básicos. Livremente, todos os buscamos, e queremos gozar da faculdade racional do autogoverno, que estrutura a noção finnisiana de liberdade. Ora, há uma desejabilidade intrínseca na autodireção, e isso constitui a autonomia individual, que se relaciona intimamente com o conceito de bem comum, o fundamento do direito:

O objetivo dos modernos sistemas de direito penal com os quais estamos familiarizados só pode ser descrito como uma certa forma ou qualidade de vida em comunidade, na qual as exigências do bem comum são de fato insistente e inequivocamente preferidas à indiferença egoísta ou à busca individualística de liberdade excessiva, mas que são também reconhecidas como incluindo o bem da autonomia individual, tal que neste modo de associação ninguém é forçado a vier sua vida em benefício ou para a conveniência de outrem, e a cada um é permitido conduzir sua própria vida (constituir a si mesmo durante seu tempo de vida) com o conhecimento e a consciência clara do modo comum apropriado e do custo de se desviar desse modo. (FINNIS, 2007, p. 256)

Os planos racionais de vida são incomensuráveis, surgindo problemas de coordenação a partir da diversidade de disputas sobre o meio mais efetivo de realizá-los. A forma mais consonante com a racionalidade prática para a resolução dos problemas de coordenação é a autoridade, e o Estado de direito é a forma de autoridade mais de acordo com a razoabilidade prática (FINNIS, 2001e).

No Postscript à segunda edição de Lei Natural e Direitos Naturais, em 2011, Finnis (2011a, p. 459) reconhece que, nesta sua primeira obra, enfatizou demasiadamente na instrumentalidade do bem comum, ressaltando que sua intenção não era a de reduzir o bem comum a um elemento puramente formal. Ao contrário, sempre percebeu nele um sentido substancial consoante a amizade política.

Neste sentido substancial, o bem comum é a realização do bem humano básico da sociabilidade, no seu nível mais abrangente, que é a comunidade política, a comunidade 
completa. A base da noção substancial de bem comum é a noção de comunidade completa, que se estuda com mais afinco em Aquinas (FINNIS, 1998). Esta obra analisa o bem comum nas duas dimensões, instrumental e substancial.

Toda obrigação reivindicada pela autoridade limitada está no oposto dos impulsos da paixão e exige uma limitação parcial da individualidade. $\mathrm{O}$ caso central da autoridade do direito é a que realiza o bem comum como superior aos bens individuais, pois sem bem comum não há bens individuais. Por isso, opor o bem comum aos bens individuais é um erro conceitual, nada obstante a sua recorrência em teorias política liberais, que criticam a concepção utilitaristaagregativa de bem comum, como bem da maioria, pautada numa ética individualista, emotivista, hedonista e relativista, como mencionado acima.

A harmonia entre as pessoas é um bem, mas a comunidade total e plena pressupõe amizade política, o compartilhamento do bem substantivo da amizade, que é a amizade com todos os cidadãos de algum modo, superando o antagonismo dos bens individuais egoísticos. Ao pertencer a uma comunidade se é integrado e educado na vida política, de modo que a comunidade não é entendida como um mal necessário, mas, ela mesma, como uma oportunidade racional de realizar o bem humano básico da sociabilidade.

A razoabilidade prática tem várias instâncias. Aquino cita três delas: (1) prudência pessoal; (2) prudência doméstica/familiar; e (3) prudência política, praticada pela autoridade e por cidadãos quando sua ação tiver repercussão política. O que está pressuposto na prudência política é a justiça geral, na qual se percebe a inserção da relevância das ações individuais nas ações políticas.

Portanto, inserir o bem comum nas ações individuais, pela virtude da justiça, confere a essa concepção ética uma solidez política e substancial. A razoabilidade prática é uma virtude moral que ordena a ação individual à consideração de todos os bens humanos, ordenando todas as virtudes. A prudência neste caso se volta ao bem comum como superior ao bem individual. A autoridade é legítima quando ela promove o bem comum, que é o bem de uma comunidade completa, que é:

comunidade global caracterizada pelas atividades coordenadas dos indivíduos, da família e da vasta rede de associações intermediárias para garantir o conjunto de condições materiais e imateriais necessárias à promoção o bem comum, e, portanto, a consubstanciação dos bens básicos na vida de cada um dos membros".(FINNIS, 2007, p. 148-149)

A comunidade completa é uma comunidade na qual todos os indivíduos podem praticar os bens humanos básicos como queiram, na medida da razoabilidade prática individual e 
pública/política, que é o que permite a compatibilização dos diversos planos de vida numa mesma sociedade. A comunidade completa tem dois requisitos: (1) o autogoverno individual, que não se confunde com uma liberdade ilimitada, articulado com (2) a comunhão existencial (FINNIS, 2007, p. 148-149). O mínimo vínculo entre os cidadãos de uma mesma comunidade é o vínculo político, que é a amizade cívica da cocidadania.

Mesmo que não haja uma amizade ou vínculo mais próximos, o vínculo de obediência às mesmas leis permanece. Contudo, pode haver relações mais próximas além daquelas do civismo, como relações na família ou nas associações acadêmicas ou esportivas, as quais possuem um bem comum interno promovidos pelos que delas participam. De todo modo, há um bem comum especial da comunidade completa política, que é integrada por cidadãos que se auxiliam na busca do bem comum, através dos direitos humanos e ditames da justiça.

A integração desses dois requisitos da comunidade completa, o autogoverno individual e a comunhão existencial, articula o bem comum nos seus aspectos instrumental (horizonte de realização racional do plano de vida) e substancial (participação ativa, pela razão pública, no bem humano da sociabilidade política, que também se pode denominar cidadania).

\section{Conclusão}

Este Artigo se dedicou a estudar a teoria da justiça de John Finnis, maior expoente contemporâneo da teoria lei natural. Esse filósofo pode ser considerado um dos protagonistas do debate em torno das contemporâneas teorias da justiça. Com efeito, poucos autores analisaram, de forma tão perseverante e profunda como ele, a questão da justificação normativa da autoridade jurídico-política do Estado para a consecução da justiça e do bem comum. Sua obra apresenta a virtude do rigor conceitual e da demonstração lógica valorizada pela tradição analítica, assim como pela tradição aristotélico-tomista.

Neste Artigo, portanto, abordamos como a questão do bem comum desponta da ética dos bens humanos básicos e da razoabilidade prática. Para isso, precisamos começar pela metodologia da teoria social proposta por Finnis, porque é ela que justifica a necessidade de se o florescimento humano pelos bens humanos básicos na teoria política reflexiva, além de analisar os contornos fundamentais da razão prática no contexto da metaética da teoria neoclássica da lei natural, proposta por Grisez.

Seguindo a estrutura argumentativa da obra-prima de Finnis (2007), Lei Natural e Direitos Naturais, formada por capítulos metodológicos ${ }^{3}$, éticos ${ }^{4}$, e jurídico-políticos ${ }^{5}$, seguimos

\footnotetext{
${ }^{3}$ Capítulos I-II.

${ }^{4}$ Capítulos III-V.

${ }^{5}$ Capítulos VI-XII.
} 
um arco lógico que intersecciona a ética dos bens humanos básicos da razoabilidade prática à autoridade do direito pela noção ético-jurídica-política do bem comum.

Não há nenhum fio solto na urdidura argumentativa de Finnis e isolar os temas dos capítulos ou dos seus numerosos artigos neutralizaria a coerência interna de um pensamento logicamente fiel às suas premissas metodológicas fundamentais. Pois, como Finnis sintetiza na introdução dos seus ensaios reunidos de filosofia do direito, o objetivo da teoria da lei natural é, precisamente:

Identificar as formas de florescimento humano, os bens humanos básicos, a interdependência entre as pessoas, a necessidade de autoridade para preservar e promover o bem comum, a desejabilidade da regulação da autoridade por um Estado de Direito, isto é, da lei positiva judicialmente interpretada e sancionada. (FINNIS, 2011n, p. 5)

Como bem humano básico, a razoabilidade prática integra o bem comum a considerações sobre os limites e possibilidades de nossa própria ação moral. Assim, pela razoabilidade prática, cada um reconhece o direito dos demais concidadãos a desenvolver seus próprios projetos de vida. Por isso, a necessidade de mediar, pela razão pública do bem comum, o eventual conflito entre autonomia individual e autoridade política.

$\mathrm{Na}$ verdade, não há conflito entre autonomia individual e autoridade pública. Ao contrário, o bem comum confere à autoridade a finalidade de promover a autonomia dos cidadãos, que convivem, tanto mais harmoniosamente quanto possível, num pluralismo, garantido pela autoridade do direito, que promove a justiça e o bem comum.

Como requisito da razoabilidade prática, o conteúdo do bem comum é o conjunto de direitos humanos, que pautam a ação jurídico-política do Estado e a nossa ação individual e social como cidadãos. Em Finnis, o bem comum é conceito central que articula a sua teoria moral dos bens humanos básicos e da razoabilidade prática com a sua teoria jurídico-política da autoridade, na modulação de uma teoria completa da justiça, abarcando a totalidade da razão prática. A investigação dos bens humanos básicos e da razoabilidade prática não se limita, porém, à dimensão ética, mas estende-se à questão jurídico-política do bem comum, que fundamenta a autoridade do Estado de Direito como realização máxima da razoabilidade prática na sua dimensão pública.

PRACTICAL REASON, LAW AND COMMON GOOD IN JOHN FINNIS' NATURAL LAW THEORY 


\begin{abstract}
Based on the hypothetical-deductive method, this paper deals with the central concepts of Finnis's theory of justice, according to his theory of substantive practical reason, whose goal is the human flourishing. The research problem is the question of the normativity of practical reason in the connection of the law and the common good. It is then necessary to reflect on the methodological nature of social theory, by contextualizing Finnis' insertion in the liberalcommunity debate, mainly because of his critique of Rawls's restrictive and excluding concept of public reason; the teleological meta-ethical foundations of practical reason are studied; it is verified as the common good emerges from the ethics of the basic human goods and the practical reasonability; the concept of the common good is articulated in its instrumental and substantial dimension, in order to emphasize the relation of freedom and social integration, by the unity of practical reason. As a result, the epistemic merit of this theory is emphasized, because of the relation of the ethics of basic human goods to the legal-political authority of the common good. The contributions are the reception of an relevant author, his conceptual deepening, with the consequent enrichment of the theoretical discussion.
\end{abstract}

Keywords: Practical reason. Common good. Law. John Finnis.Natural Law.

\title{
Referências
}

AQUINO, Tomás de. Suma Teológica. Vol. 4: I Seção da II Parte, questões 49-114. $2^{\mathrm{a}}$ ed. São Paulo: Loyola, 2010, p. 527-528 (q.90, a.4).

AIYAR, S. "The problem of law's authority: John Finnis and Joseph Raz on legal obligation". Law and Philosophy, vol. 19, pp. 465-489, 2000.

BARZOTTO, L. Filosofia do direito. Os conceitos fundamentais e a tradição jusnaturalista. Porto Alegre: Livraria do Advogado, 2010.

COELHO, André; "Lei natural e direitos naturais - Cap. 1". http://aquitemfilosofiasim.blogspot.com/2016/11/lei-natural-e-direito-natural-cap-1.html (Acesso em 26 de outubro de 2018).

CHALMETA, Gabriel. La justicia política en Tomás de Aquino: una interpretación del bien común político. Pamplona: EUNSA, 2002.

CORDIOLI, Leandro. "A razoabilidade prática e o valor da justiça em John Finnis: reaproximação a um modelo de justiça personalista e ético". In: WEBER, Thadeu; MIZUTA, Alessandra; PROENÇA, Fabricio (org,). Princípios fundamentais de justiça. Curitiba: Juruá, 2015. p.23-50.

CORREAS, Carlos I. Massini. "La concepción normativa del gobierno del Derecho: nuevas objeciones al rule of law y una respuesta desde las ideas de John Finnis". Persona y Derecho, vol. 73, pp. 203-230, 2015.

. "Iusnaturalismo, razón práctica y objetividade del derecho". In: La ley natural y su interpretación contemporánea. Pamplona: EUNSA, 2006. 
CROWE, J. "Natural Law Theories". Philosophy Compass, vol. 11/2, pp. 91-101, 2016.

DUKE, George. 'Finnis on the Authority of Law and the Common Good'. Legal Theory, vol. 19, pp. 44-62, 2013.

FERREIRA NETO, Arthur Maria. Metaética e a fundamentação do direito. Porto Alegre: Elegantia Juris, 2015.

FINNIS, John. Fundamentos de ética. Rio de Janeiro: Elsevier, 2012. . Natural law and natural rights. 2a ed. Oxford: Oxford University Press, $2011 \mathrm{a}$. .. Collected Essays: 5 volumes. Oxford: Oxford University Press, $2011 \mathrm{~b}$.

. John Rawls' A theory of justice. In: Human rights and common good. Collected Essays: Vol. III. Oxford: Oxford University Press, 2011c. p. 72-75.

. Religion and Public Reasons. Collected Essays: vol. V. Oxford: Oxford University Press, 2011d.

. "Limited government". In: Human rights and common good. Collected Essays: Vol. III. Oxford Press, 2011e.

. "Public Reason and moral debate (1998)". In: Reason in action. Collected Essays: vol. I. Oxford: Oxford Press, 2011f.

. "Natural Law (1996)". In: Reason in action. Collected Essays: vol. I. Oxford: Oxford University Press, $2011 \mathrm{~g}$.

. "Limited government". In: Human rights and common good. Collected Essays: Vol. III. Oxford: University Press, $2011 \mathrm{~h}$.

. "The authority of law in the predicament of contemporary social theory". In: Philosophy of law. Collected essays, vol. III. Oxford: Oxford University Press, 2011i. p. 46-65.

. "Religion and State (2006)". In: Religion and Public Reasons. Collected Essays: vol. V. Oxford: Oxford University Press, 2011j, p. 80-102.

. "A grand tour of legal theory". In: Philosophy of law. Collected essas vol. 4. Oxford: Oxford University Press, 2011j.

. "Legal reasoning as practical reasoning”. In: Reason in action. Collected Essays: vol. I. Oxford: Oxford University Press, 20111.

. "Law as Coordination". In: Philosophy of law. Collected essays, vol. III. Oxford: Oxford University Press, $2011 \mathrm{~m}$. p. 66-73.

. Philosophy of law. Collected essays vol. 4. Oxford: Oxford University Press, $2011 \mathrm{n}$. . Lei natural e direitos naturais. São Leopoldo: Unisinos, 2007. . Aquinas. Moral, legal and political theory. Oxford: Oxford University Press, 1998. 
.; BOYLE, Joseph; GRISEZ, Germain. Practical principles, moral truth and ultimate ends. American Journal of Jurisprudence, vol. 32, 1987a, p. 99-151.

. Nuclear deterrence, morality and realism. Oxford, Oxford University Press, 1987b.

GARGARELLA, Roberto. Teorias da justiça depois de Rawls. São Paulo: Martins Fontes, 2008.

GEORGE, Robert P. Making men moral. Civil liberties and public morality. Oxford: Oxford University Press, 1993.

. (ed.). Natural law theories: contemporary essays. Oxford: Oxford University Press, 1992.

GREEN, Leslie. 'The Nature of Limited Government'. In: GEORGE, R. P.; KEOWN, J. (eds.). Reason, Morality, and Law: The Philosophy of John Finnis. Oxford: Oxford University Press, 2013. p. 186-203.

GRISEZ, Germain. "The First Principle of Practical Reason: A Commentary on the Summa Theologiae, 1-2 Question 94, Article 2". Natural Law Forum, vol. 10, 1965, p. 168-201.

KEOWN, John; Robert P. GEORGE (eds.). Reason, Morality, and Law: The Philosophy of John Finnis. Oxford: Oxford University Press, 2013.

KYMLICKA, W. Filosofia política contemporânea. São Paulo: Martins Fontes, 2006.

MACINTYRE, Alasdair. Depois da Virtude: Um Estudo em Teoria Moral. Bauru: EDUSC, 2001.

MIRANDA, John Florindo de. Da lei natural como fundamento supramoral da ação humana em John Finnis: Considerações sobre metodologia, teoria normativa e aspectos fundacionais. Dissertação (Mestrado em Filosofia). Instituto de Filosofia, Sociologia e Política da Universidade Federal de Pelotas, Pelotas, 2015.

MURPHY, M. “The Common Good”. Review of Metaphysics vol. 59, pp. 133-164, 2005.

NOZICK, Robert. Estado, Anarquia e Utopia. São Paulo: Martins Fontes, 2011.

OLIVEIRA, Elton Somensi de. Bem Comum, Razão Prática e Direito: A fundamentação do conceito de bem comum na obra de John M. Finnis. 2002. Dissertação (Mestrado em Direito) Programa de Pós-Graduação em Direito, Universidade Federal do Rio Grande do Sul, Porto Alegre.

POSTEMA, Gerard. Legal philosophy in the twentieth century: The common Law World. New York: Springer 2011, p.551-562.

RAWLS, John. Uma teoria da justiça. São Paulo: Martins Fontes, 2002.

SANDEL, Michael. Liberalismo e os limites da justiça. Lisboa: Calouste Gulbenkian, 2005.

SCANDROGLIO, Tommaso. La teoría neoclassica sulla legge naturale di Germain Grisez e John Finnis. Torino: G. Giappichelli Editore, 2012. 
VALLEJO, Iván Garzón. "Bien común, pluralismo y derechos”. In: Etcheverry, Juan B. (ed.) Ley, moral y razón. Estudios sobre el pensamiento de John M. Finnis a propósito de la segunda edición de Ley natural y derechos naturales. México: Universidad Nacional Autónoma de México, 2013. pp. 141-160.

ZANIN, Fabrício Carlos; MIZUTA, Alessandra. "A teoria da justiça de John Rawls e as contradições do liberalismo: a difícil ação de despir-se das vestes metafísicas". In: WEBER, Thadeu; MIZUTA, Alessandra; PROENÇA, Fabricio (org,). Princípios fundamentais de justiça. Curitiba: Juruá, 2015. p.23-50.

Trabalho recebido em 20 de dezembro de 2018 Aceito em 14 de fevereiro de 2019 